www.jmscr.igmpublication.org

Impact Factor 5.84

Index Copernicus Value: 83.27

ISSN (e)-2347-176x ISSN (p) 2455-0450

crossref DOI: _https://dx.doi.org/10.18535/jmscr/v5i8.39

Journal Of Medical Science And Clinical Research

\title{
Epidemiology of Oral cancer-A Hospital based case control study in Bengaluru
}

\author{
Authors \\ Vijay C R $\mathbf{R}^{1}$, Dr Lokesh $\mathbf{V}^{2}$, Dr Ramesh $\mathbf{C}^{3}$, Dr P Sridhar ${ }^{4}$, Dr Mahanthesh A $\mathbf{S}^{5}$ \\ ${ }^{1}$ Assistant Professor, Department of Epidemiology and Biostatistics, Kidwai Cancer Institute, Bengaluru \\ ${ }^{2}$ Professor and Head, Department of Radiation Oncology, Kidwai Cancer Institute, Bengaluru \\ ${ }^{3}$ Professor and Head, Department of Epidemiology and Biostatistics, Kidwai Cancer Institute, Bengaluru \\ ${ }^{4}$ Assistant Professor, Department of Radiation Oncology, Kidwai Cancer Institute, Bengaluru \\ ${ }^{5}$ Assistant Surgeon, Kidwai Cancer Institute, Bengaluru \\ Corresponding Author \\ Dr P Sridhar
}

Assistant Professor, Department of Radiation Oncology, Kidwai Cancer Institute, Bengaluru

\begin{abstract}
Back Ground of the Study: Oral cancer is estimated to be the fifteenth most common cancer and it accounts an age adjusted rate (AAR) of 4.0 persons for every 100,000 population after combining both sexes in global level. In Asia, Oral and lip cancer is ranked ninth most common cancer with AAR 3.8 in both sex. In India oral cancer is found to be third leading site after combining both sex (AAR 7.2), in males it occupies Ist position with AAR 10.1 in females 5th leading position with AAR 4.3 per 100,000 persons. In Hospital based cancer registry (HBCR) oral cancer showed increasing proportion among tobacco related cancer in both sex. Oral cancer is twice as common in men as in women. This difference may be related to the use of alcohol and tobacco in Kidwai hospital based cancer registry and the proportion of male and female oral cancer is same. This study was conducted to know the risk factors associated for oral cancer pattern.

Material and Methodology: The study was conducted in Kidwai cancer Institute located in Bengaluru, which is the capital of the state of Karnataka. It is comprehensive center for cancer research and treatment in the state and is one of the Regional cancer center in India. To study risk factors, prospective case control study was plan Ned. The information on exposure factor was collected through direct personal interview method using structure questionnaire prepared based on old review and experts opinion. Only microscopically confirmed cases were including in the study, one case per control was matched for sex and age group was selected. 300 cases and equal number of control selected for the study. A descriptive statistics along with odds ratio estimate the effects of different variables on oral cancer.

Results: There were more proportion of women (55\%) than men (44\%). The mean age group of respondents is 54 years. About $67 \%$ of cases and $44 \%$ of controls are illiterates and $4 \%$ in study group and $14 \%$ in control groups have completed their college level education. The average income level of cases and controls is $1700 \mathrm{Rs} / \mathrm{month}$ and 3600 Rs/month respectively. Among 600 respondents, $74 \%$ and $26 \%$ are tobacco users either in the form of chewing or smoking tobacco. Out of 288 respondents, majority of the cases have tobacco chewing habit (78\%) compared to control group which was 22\%. $66 \%$ of the cases and 33\% of controls have smoking habits out of 125 respondents. Odds ratio was found to be significant 2.3 and 10.8 between cases and controls with respect to chewing and smoking habits. The odds ratio between cases and control with respect to only smoking, alcohol and Smoking+Alcohol consumption was not found significant. Only chewing, smoking +chewing and smoking+chewing +alcohol was found significant (P-values 0.001, 0.033, 0.001). Majority of them had the habit of chewing tobacco stem (Kaddipudi) with
\end{abstract}


lime and betel leaf. Among 64 respondents, tobacco chewing in the form of leaf (Khaini) 43(67.2\%) and 21 (32.8\%) with respect to case and control, the odds ratio is statistically significant.

Conclusion: In this study, a higher chance of oral cancer was found in those who were chewing and smoking tobacco in any form and a strong risk for oral cancer is proved from chewing with different combination. Alcohol and smoking alone has not proved the association with oral cancer, it may be due to high proportion of women respondents or combined males and female respondents for analysis.

Keywords: Case control study, AAR-age adjusted rates, Annual percentage change, Hospital based cancer registry, Odds ratio, Tobacco related cancer.

\section{Introduction}

Oral cancer is estimated to be the fifteenth most common cancer in the world. It accounts for an age adjusted rate (AAR) of 4.0 persons for every 100,000 population, after combining both sexes in global level. In Asia, Oral and Lip cancer is ranked ninth most common cancer with AAR of 3.8 in both sex. However, it is relatively rare in European and North American countries. In India oral cancer is found to be third leading site after combining both sex (AAR 7.2). In males, it occupies $1^{\text {st }}$ position with AAR 10.1 and in females $5^{\text {th }}$ leading position with AAR 4.3 per 100,000 persons ${ }^{(1)}$. In Population based cancer registry, tobacco related cancer incidence rates decreased among women significantly [annual percentage changes (APC $-0.65 \%$ ), though not among men (APC - $0.10 \%$ ).

In HBCR, increasing trend in tobacco related cancer is observed in males. Most of the tobacco related cancer sites showed increasing trend in oral cavity and lung in females. Age of diagnosis is less in rural area compared to urban ${ }^{(2)}$. In Population based cancer registry of Bengaluru (PBCR), the mouth cancer trend in both males and females is showing decreasing trend, where as tongue cancer is showing increasing trend ${ }^{(3)}$. In hospital based cancer registry, all oral cancer percentage is increasing every year ${ }^{(4)}$.

Oral cancer is twice as common in men as in women. This difference may be related to the use of alcohol and tobacco, a major oral cancer risk factor that is seen more commonly in men than women. In Kidwai hospital based cancer registry, more women oral cancer cases were registered compared to men. More than $80 \%$ of oral cancer patients come to Kidwai Cancer Institute from rural and semi urban area (Other than Bengaluru) hence, this study was conducted to know the risk factors associated with increasing Oral cancer pattern.

\section{Material and Methodology}

The study was conducted in Kidwai Cancer Institute, located in Bengaluru, which is the capital of the state of Karnataka. It is comprehensive center for cancer research and treatment in the state and is one of the Regional cancer centers in India. To study risk factors, prospective matched Case control study was planned.

A case was defined as a person aged more than 25 years and above with pathologically confirmed primary diagnosis of Oral cancer according to ICD10. Cases selected randomly that were histopathologically diagnosed as oral cancer on or after January 2015 to June 2017 visited the hospital during the study period were included.

A control was defined as a person aged more than 25 years who visited Kidwai Cancer hospital along with cancer patient. People with any other malignancy and/or people suffering from any disease associated with the study exposures were excluded.

The information on exposure factor was collected through direct personal interview method using structure questionnaire prepared based on old review and experts opinion. Data was collected during first presentation of patients at the time of registration and simultaneously from the attendants of cancer cases staying at ambulatory patient home. Among the suspect cases, those cases after microscopic confirmation were included in the study, one case per control was matched for sex and age group was selected. 300 
cases and equal number of control was selected for the study.

\section{Analysis}

Difference between case and control with respect to habitat and diet factor was analysed using $\mathrm{R}$ statistical software. A descriptive statistics along with odds ratio estimate, the effects of different variables on Oral cancer. Univariate analysis was done to find the effect of each variable ${ }^{(5)}$.

\section{Results}

Fig- 1 shows the distribution of case and control group with respect to sex. There were more females (55\%) than males (44\%). 300 cases and equal number of controls are selected for the study. The mean age group of respondents is 54years, similar age distribution was observed between cases and control. About $67 \%$ of cases and $44 \%$ of controls are illiterates, about $18 \%$ in study group and $19 \%$ in control groups completed primary education, $10 \%$ in cases and $21 \%$ in controls completed their secondary education. Only $4 \%$ in study group and $14 \%$ in control groups completed their college level education. The average income level of cases and controls is $1700 \mathrm{Rs} /$ month and $3600 \mathrm{Rs} /$ month respectively.

Table-1 shows that, among 600 respondents, about $74 \%$ and $26 \%$ are tobacco users either chewing or smoking tobacco. Out of 288 subjects, majority of the cases are habitual tobacco chewers (78\%), compared to control group (22\%). $66 \%$ of the cases and $33 \%$ controls have smoking habits out of 125 respondents, odds ratio is found significant 10.8 and 2.3 between cases and controls with respect to chewing and smoking habits.

Table-2 gives the distribution of different combination of habits among the 300 cases, 59\% had the only chewing habit compared to $19 \%$ among controls. Among the 24 cases, $8.0 \%$ had the habit of smoking compared to $6.0 \%$ among the controls. The odds ratio between cases and control with respect to only smoking, alcohol and Smoking+Alcohol consumption is not found significant with $5 \%$ level of significance. Only chewing, smoking+chewing and smoking+chewing+alcohol was found significant (P-values 0.001, 0.033, 0.001).

Further univariate analysis was carried out to know the effect of different chewing habits. Out of 284 chewing habits in cases and controls, ). Majority of them had the habit of chewing tobacco stem (Kaddipudi) with lime and betel leaf. Among 64 respondents, tobacco chewing in the form of leaf (Khaini) 43(67.2\%) and 21 (32.8\%) with respect to case and control, the odds ratio is statistically significant. The detailed analysis showed in table-3.

Table No1: Different types of Tobacco and Alcohol Habits in Cases and Control

\begin{tabular}{|l|c|c|c|c|c|c|c|}
\hline \multirow{2}{*}{ Habits } & \multicolumn{2}{|c|}{ Cases (300) } & \multicolumn{2}{c|}{ Control (300) } & \multirow{2}{*}{ Total } & $\begin{array}{c}\text { Odds } \\
\text { Ratio }\end{array}$ & \multirow{2}{*}{ P-value } \\
\cline { 2 - 8 } & $\#$ & $\%$ & $\#$ & $\%$ & 125 & 2.3 & 0.001 \\
\hline Smoking Tobacco & 83 & 66.4 & 42 & 33.6 & 125 & 0.001 \\
\hline Chewing Tobacco & 224 & 77.8 & 64 & 22.2 & 288 & 10.8 & \\
\hline Any Form Tobacco & 274 & 74.3 & 105 & 25.7 & 379 & & \\
\hline Alcohol & 74 & 64.9 & 40 & 35.1 & 114 & 2.1 & 0.005 \\
\hline
\end{tabular}

Table No 2: Different Forms of Combination in Cases and Control

\begin{tabular}{|l|c|c|c|c|c|c|c|}
\hline \multirow{2}{*}{ Habits } & \multicolumn{2}{|c|}{ Cases } & \multicolumn{2}{c|}{ Control } & Total & Odds & \multirow{2}{*}{ P-value } \\
\cline { 2 - 7 } & $\#$ & $\%$ & $\#$ & $\%$ & $\#$ & Ratio & \\
\hline Only Smoking & 24 & 8.0 & 18 & 6.0 & 42 & 1.7 & 0.2752 \\
\hline Only Chewing & 177 & 59.0 & 58 & 19.3 & 235 & 9.2 & 0.001 \\
\hline Only Alcohol & 5 & 1.7 & 13 & 4.3 & 18 & 0.1 & 0.106 \\
\hline Smoking+Chewing & 15 & 5.0 & 7 & 2.3 & 22 & 4.4 & 0.033 \\
\hline Smoking+Alcohol & 12 & 4.0 & 7 & 2.3 & 19 & 2.8 & 0.184 \\
\hline Smoking+Chewing+Alcohol & 31 & 10.3 & 9 & 3.0 & 40 & 11.4 & 0.001 \\
\hline No Habit & 23 & 7.7 & 186 & 62.0 & 209 & 0.01 & 0.001 \\
\hline Total & 300 & 100 & 300 & 100 & 600 & & \\
\hline \hline
\end{tabular}


Table No 3: Different Forms of Chewing Habits in Cases and Control

\begin{tabular}{|l|c|c|c|c|c|c|c|}
\hline \multirow{2}{*}{ Habits } & \multicolumn{2}{|c|}{ Cases } & \multicolumn{2}{c|}{ Control } & \multirow{2}{*}{ Total } & $\begin{array}{c}\text { Odds } \\
\text { Ratio }\end{array}$ & \multirow{2}{*}{ P-value } \\
\cline { 2 - 7 } & $\#$ & $\%$ & $\#$ & $\%$ & & 5.4 & 0.003 \\
\hline Only Gutka (A) & 12 & 70.6 & 5 & 29.4 & 17 & 4.1 & 0.001 \\
\hline Only Tobacco Leaf (B) & 43 & 67.2 & 21 & 32.8 & 64 & 9.8 & 0.001 \\
\hline Only Tobacco Steam+Lime (C) & 83 & 90.2 & 9 & 9.8 & 92 & 8.8 \\
\hline Chewing Habit & 226 & 79.6 & 58 & 20.4 & 284 & 20 & 0.001 \\
\hline Chewing Habit+Liquore & 61 & 71.8 & 24 & 28.2 & 85 & 6.3 & 0.001 \\
\hline No Chewing Habit & 67 & 22.9 & 226 & 77.1 & 293 & 0.08 & 0.001 \\
\hline
\end{tabular}

Fig1: Gender wise Distribution of Cases and Control

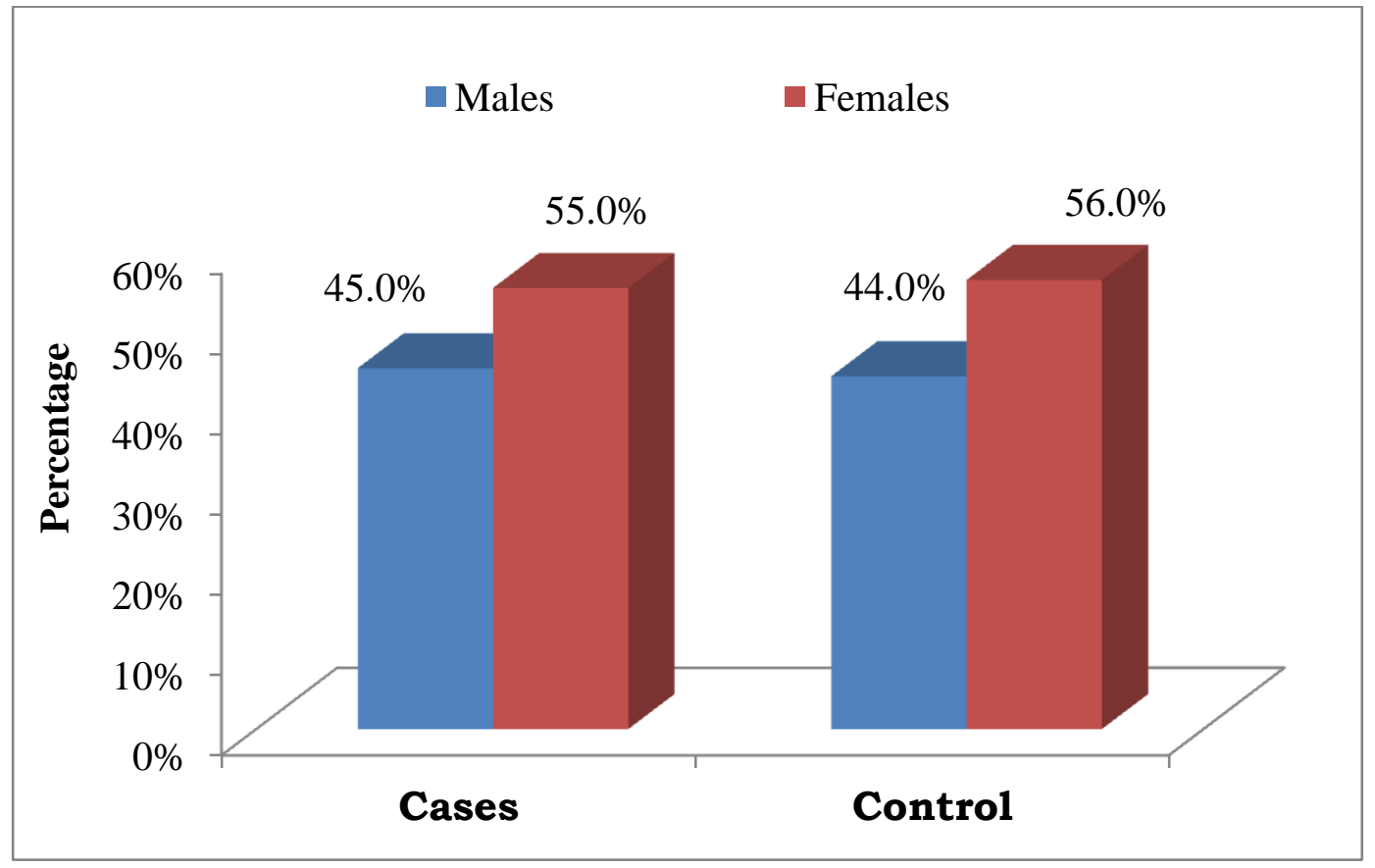

\section{Discussion}

The respondent who have smoking habit were 2.3 times more likely to get oral cancer compared to people who did not smoke, the findings were similar to study conducted at Pune by Madani A.H et al, the frequency of smoking in cases were significantly higher than control group ${ }^{(6)}$. Only smoking and smoking with alcohol fails to establish association, many others studies have proved association between smoking tobacco which causes oral cancer ${ }^{(8-9)}$, the reason for failure in association between smoking and oral cancer may be due to high proportion of women in this study. The study conducted by P C Guptha.et al showed very minimal Self-reported tobacco use among males was as follows: urban $35.2 \%$; urbanslums $48.3 \%$; and rural $52.6 \%$ ( $P$ value $<0.05)$. Self-reported tobacco use among females was as follows: Urban 3.5\%; urban-slums 11.9\%; and rural $17.7 \%$ ( $P$ value $<0.05$ ). More males reported daily bidi (tobacco wrapped in temburini leaf) smoking (urban $17.8 \%$, urban-slums $36.7 \%$, rural $44.6 \%$ ) than cigarette use (urban 9.6\%, urbanslums $6.3 \%$, rural $2.9 \%$ ). Females using smoked tobacco were almost exclusively using bidis (urban $1.7 \%, 7.9 \%, 11 \%$ in rural) ${ }^{(10)}$.

Chewing+alcohol groups had 4.4 times higher risk of getting oral cancer than controls. In those who were involved in Chewing + alcohol + smoking habit, the risk was 11.4 times more than the controls. The synergistic effects of alcohol, tobacco and betel quid on oral cancer is clearly demonstrated ${ }^{(11)}$. Similar study in Trivandrum showed the adjusted odds ratios (ORs) for chewers were $3.1 \quad(95 \%$ confidence interval $(\mathrm{CI})=2.1-4.6)$ for men and $11.0(95 \% \mathrm{CI}=5.8$ 
20.7) for women. Effects of chewing pan with or without tobacco on oral cancer risk were elevated for both sexes.

Bidi smoking increased the risk of oral cancer in men $(\mathrm{OR}=1.9,95 \% \mathrm{CI}=1.1-3.2)$. Dose-response relations were observed for the frequency and duration of chewing and alcohol drinking, as well as in duration of bidi smoking. Given the relatively poor survival rates of oral cancer patients, cessation of tobacco and moderation of alcohol use remain the key elements in oral cancer prevention and control ${ }^{(12)}$. The clear positive association exists between tobacco use in any form with oral cancer, A positive association of getting Oral cancers was 5.4 times observed in gutka users compared with non gutka users ${ }^{(13)}$. Similarly any other tobacco chewing increases the risk of oral cancer ${ }^{(14)}$.

\section{Conclusion}

In this study, a higher chance of oral cancer was found in those who were chewing tobacco and smoking in any form and a strong risk for oral cancer is proved from chewing. Alcohol and smoking alone has not proved the association with oral cancer. It may due to high proportion of women sample or combined both the sex for analysis.

\section{References}

1. Ferlay J, Soerjomataram I, Ervik M, Dikshit R, Eser S, Mathers C, Rebelo M, Parkin DM, Forman D, Bray, F. GLOBOCAN 2012 v1.0, Cancer Incidence and Mortality Worldwide: IARC Cancer Base No. 11 [Internet]. Lyon, France: International Agency for Research on Cancer; 2013. Available from: http://globocan.iarc.fr, accessed on day/month/year.

2. Vijay $\mathrm{C} R$, Tobacco related Cancer trends in Bangalore, India. British Journal of Pharmaceutical and Medical Research Vol.01, Issue, 02, Pg.72-79, SeptemberOctober 2016.
3. Five year consolidated report of Population based cancer registry 2007-11: Kidwai Cancer Institute, Bengaluru, 2015.

4. Annual report of Hospital based cancer registry 2013: Kidwai Cancer Institute, Bengaluru, 2016.

5. TR Saraswathi, $K \quad$ Ranganathan, $S$ Shanmugam, R Sowmya, Prem Deepa Narasimhan, R Gunaseelan "Prevalence of oral lesions in relation to habits : Crosssectional study in South India" Indian Journal of Dental Research, 2006, Vol. 17, 3, 121-126

6. Madani AH, Dikshit M, Bhaduri D. Risk for oral cancer associated to smoking, smokeless and oral dip products. Indian $\mathbf{J}$ Public Health 2012;56:57-60.

7. Sandeep Mahapatra ${ }^{1}$, Ramachandra Kamath $^{1}$, Bharatesh K Shetty ${ }^{2}$, VS Binu ${ }^{3}$. Risk of oral cancer associated with gutka and other tobacco products: A hospitalbased case-control study. J can Res ther 2015:11, 199-2003.

8. S. Jane Henley, Michael J. Thun, Ann Chao and Eugenia E. Calle. "Association Between Exclusive Pipe Smoking and Mortality From Cancer and Other Diseases". Oxford Journals Medicine \& Health JNCI: Jnl of National Cancer Institute Volume 96, Issue 11 Pp. 853861.

9. Sharma MK, Gour N, Pandey A, Wallia D. Epidemiological study of risk factors for oral, laryngeal and esophageal cancers at a tertiary care hospital in India. Asian Pac J Cancer Prev 2011;12:1215-8.

10. Vivek Gupta, Kapil Yadav, and K Anand. "Patterns of Tobacco Use Across Rural, Urban, and Urban-Slum Populations in a North Indian Community". Indian J Community Med. 2010 Apr; 35(2): 245251.

11. Ying-Chin Ko, Yung-Li Huang, etall. "Betel quid chewing, cigarette smoking and alcohol consumption related to oral 
cancer in Taiwan. November 1995,

Volume 24, Issue 10, November 1995 , Pages 450-453

12. Richard Muwonge ${ }^{\mathrm{a}}$, Kunnambath Ramadas". et al. "Role of tobacco smoking, chewing and alcohol drinking in the risk of oral cancer in Trivandrum, India: A nested case-control design using incident cancer cases". Oral Oncology Volume 44, Issue 5, May 2008, Pages 446454.

13. VS Binu', Ramachandra Kamath ${ }^{2}$, Sandeep Mahapatra ${ }^{2}$, Bharatesh K Shetty ${ }^{3}$ " Risk of oral cancer associated with gutka and other tobacco products: A hospitalbased case-control study". Journal of Cancer Research and Therapeutics, Vol. 11, No. 1, January-March, 2015, pp. 199203.

14. Dr. Paolo Boffetta MD a.Prof. Stephen Hecht $\mathrm{PhDb}$, etall. "Smokeless tobacco and cancer". The lancet oncology. Volume 9, Issue 7, July 2008, Pages 667-675. 